\title{
Introduction to Future Networks Management Architectures and Mechanisms
}

\author{
Iztok Starc \\ Faculty of Computer and Information Science, University of Ljubljana, Slovenia \\ iztok.starcefri.uni-lj.si
}

In this chapter, current issues of the Internet are addressed and arising problems of future Internet from socio-technical point of view are tackled. The future Internet considered as a Next Generation Network (NGN) will provide integrated services, i.e. interactive, multimedia, data, real-time, and mobile services. The focus will be placed on the end-user for whom this information and communications technologies (ICT) are primarily designed for. The user's dependence on ICT is rising, being tied to increasing complexity of critical infrastructures (CIs) interdependencies. No wonder that also other stakeholders (service providers and network operators) have to be in the focus.

The future Internet as NGN will only be successful if requirements of users, service providers and network operators are taken into account, and economic and legislative aspects are considered as well. In addition to providing equality of access right so that end-users have the opportunity to choose the most effective service provider, marginalized groups have to be considered as well. They are entitled to participate in social life and thus, broadband has to be provided not only in densely populated areas but also in rural areas. According to aforesaid requirements, we propose several socio-technical solutions, possible alternative choices or improvements to existing ones that will be presented in the chapter outline below, all intended to improve productivity and efficiency of services, security of stakeholders and end-user satisfaction. These selected issues will involve one or more stakeholders and will be related to ICT problems.

In Section 1 on "Economics of Quality of Experience" by P. Reichl, B. Tuffin, and P. Maillé, focus is on the human factor, i.e. quality of experience and its economic implications. This section claims that QoE is a better representation of user's perception than traditional Quality of Service estimation. A better understanding of links between the quality as delivered by the network, as perceived by the user, and as valued by the market can be justified by the logarithmic utility.

Electronic business in the Internet has become an important driver for economic growth. The work on a "Decision Support in Contract Formation for Commercial Electronic Services with International Connection" in Section 2 by M. Waldburger and B. Stiller addresses jurisdiction and applicable law issues of international contracts between consumers and service providers in the case of electronic services. This section proposes a decision support system which provides recommendations on contract parameters at the time of contract formation. 
Section 3 on "Competition among Telecommunication Providers" by P. Maillé, P. Reichl, and B. Tuffin analyzes a competition between providers implementing a congestion-pricing scheme in various real-life scenarios. The convergence of networks, where Internet, wired and wireless telephony and television are regrouped into a single network, poses additional economic challenges related to providers' competition. In this situation, each network operator has to adapt its pricing scheme in order to attract customers, to maximize revenue and/or to allow fairness in the way resources are shared, but taking care of the decision of competitors who can lure customers.

Section 4 by F. Hecht and B. Stiller on "Economic Traffic Management: Mechanisms and Applications" proposes economic traffic management mechanisms (ETM) to enable competitive overlay services and their management that in order to achieve benefits to end-users, service providers and network operators applied to live and on-demand video streaming as a promising use case. Due to large traffic increases, service providers and network operators need to control and manage network traffic stemming from overlaybased applications.

Section 5 on "Autonomic Management of Mobile and Wireless Networks" by A. M. Hadjiantonis summarizes cooperating autonomic management mechanism for wireless and mobile networking in the future Internet. The principles of autonomic management and self-organization are envisioned by researchers as a natural path for the Future Internet. Autonomic management (or self-management) capabilities aim at relieving service providers, network operators and end-users from tedious configuration and troubleshooting procedures.

Section 6 on "On the Provision of Advanced Telecommunication Services in Rural Areas" by L. Lambrinos focuses on telecommunications in rural areas. Telecommunication operators are not prepared to invest in areas that are not profitable and have only a small number of inhabitants, or places that are remote and infrastructure development costs are high. As a result there are many areas in the world lacking access to the latest telephony and internet technologies. For two different real-life scenarios, a solution is proposed for providing marginalized groups access to features that would not have been available otherwise.

The work on "Electrical Power Systems Protection and Interdependencies with ICT" in Section 7 by G.M. Milis, E.Kyriakides and A.M. Hadjiantonis introduces the need to protect critical infrastructures in order to maintain the economic and secure wellbeing of our society. In this context, the interdependencies between ICT and Electric Power Systems are examined.

Section 8 on "Towards Quantitative Risk Management for Next Generation Network" by I. Starc and D. Trček addresses the reasons why information systems security situation is worsening at an alarming rate and how can proactive, quantitative and computerized risk management approaches overcome this problem, and make information security measurable and manageable.

Open Access. This article is distributed under the terms of the Creative Commons Attribution Noncommercial License which permits any noncommercial use, distribution, and reproduction in any medium, provided the original author(s) and source are credited. 